ISSN: 2638-5279

Volume 3, Issue 1, 2020, PP: 05-10

\title{
Segmentation Analysis of Sensor Glucoses and their Associated Energy (GH-Method: Math-Physical Medicine)
}

\begin{abstract}
*Corresponding Author: Gerald C. Hsu, eclaireMD Foundation, USA.
\section{INTRODUCTION}

This paper describes the results from the sensor glucoses collected by utilizing the continuous glucose monitoring (CGM) device and its segmentation analysis by using energy theory from mechanical engineering.
\end{abstract}

Gerald C. Hsu

eclaireMD Foundation, USA.

\section{MethodS}

Since 5/5/2018, the author has measured his glucose values using a CGM device on his upper arm and checked his glucose measurements $\sim 80$ times each day. For a duration of 703 days, from 5/5/2018 to $4 / 8 / 2020$, he has collected 56,240 glucose data. He then segmented each day's 80 data into the following seven subcategories:

(1) Fasting FPG: 7.5 hours (23:30-07:00)

(2) Breakfast PPG: 3.0 hours (07:00-10:00)

(3) Pre-lunch: 2.0 hours (10:00-12:00)

(4) Lunch PPG: 3.0 hours (12:00-15:00)

(5) Pre-dinner: 3.0 hours (15:00-18:00)

(6) Dinner PPG: 3.0 hours (18:00-21:00)

(7) Pre-bed: 2.5 hours (21:00-23:30)

Total hours per day: 24 hours (23:30 previous day 23:30 present day)

He has further assembled three PPG subcategories into one PPG category along with assembling prelunch subcategory and pre-dinner subcategory into a pre-meals category.

Here are the four categories:

(A) FPG Category: 7.5 hours

(B) PPG Category: 9.0 hours
(C) Pre-meals Category: 5.0 hours

(D) Pre-bed Category: 2.5 hours

After using the computer software to calculate the average glucose value for each glucose category, he has then multiplied the group's average glucose value with the time duration for each one (i.e. to obtain the area underneath glucoses curve during each category's timespan) to get a relative energy level, which is associated with those individual glucoses within the time duration.

\section{RESULTS}

Figure 1 shows the daily average sensor glucose, 90-days moving average glucose, and the so-called "candlestick glucoses" during this period of 703 days. This unique "candlestick" model was created by a Japanese rice trader around 200 years ago and later imported by an American trader to be used by the Wall Street stock market in early 1990's. In a single combined diagram, it displays five vital glucose values together, open day's glucose, close day's glucose, highest glucose, lowest glucose, and daily average glucose, which is similar to the five stock prices in one candlestick consisting of open price, close price, maximum price, minimum price, and average price.

Figure 2 illustrates the comparison of a synthesized (i.e. summarized) daily glucose chart from 23:00 of previous day throughout 23:00 of the present day, and the average glucose of seven subcategories chart. These two curves have a high correlation between them, but with some differences between straight lines connecting all of the average values and all of these detailed glucose data connection during each subcategory's segment. 
Segmentation Analysis of Sensor Glucoses and their Associated Energy (GH-Method: Math-Physical Medicine)

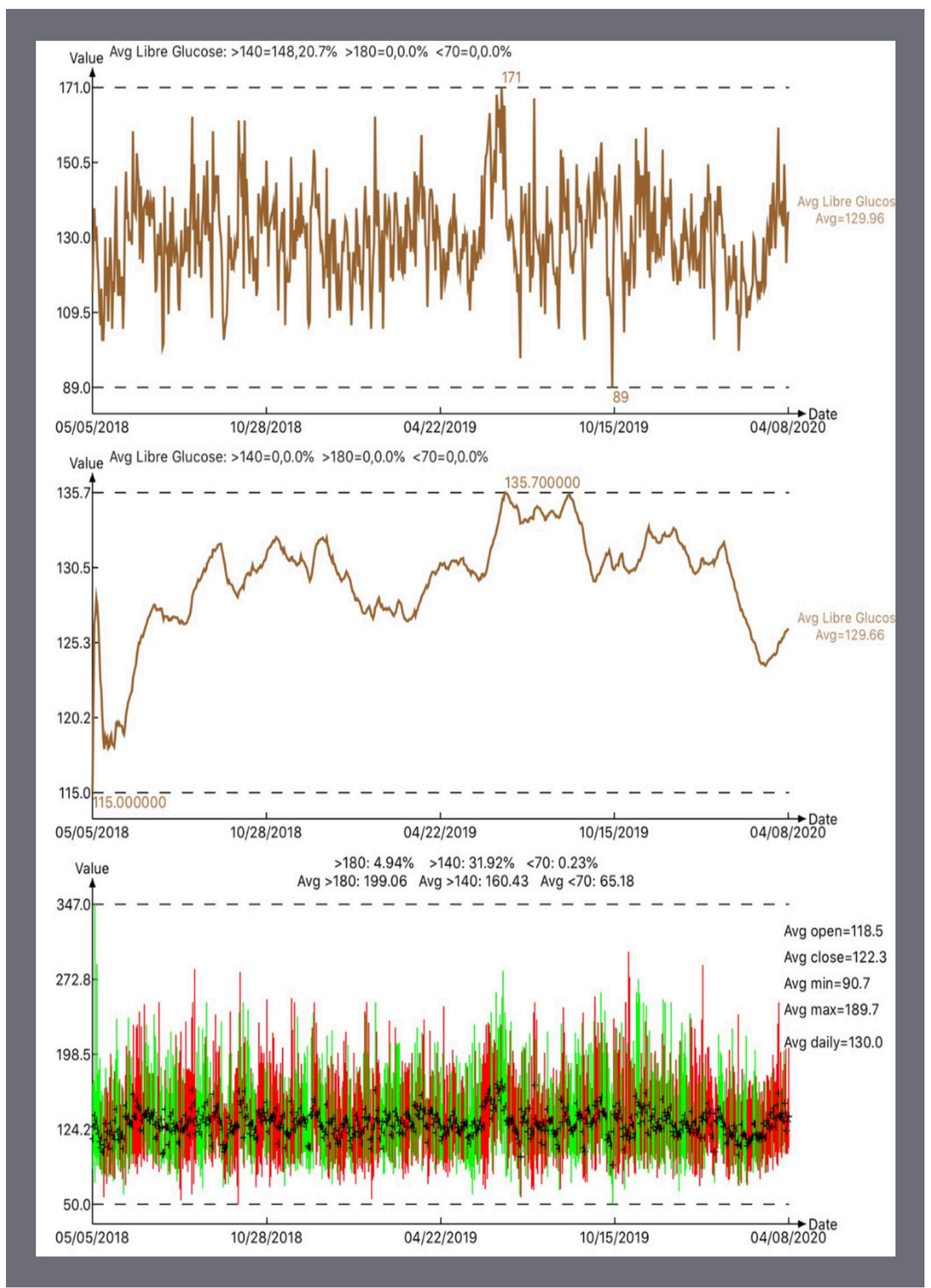

Figure1. 3 kinds of Daily average glucose 
Segmentation Analysis of Sensor Glucoses and their Associated Energy (GH-Method: Math-Physical Medicine)

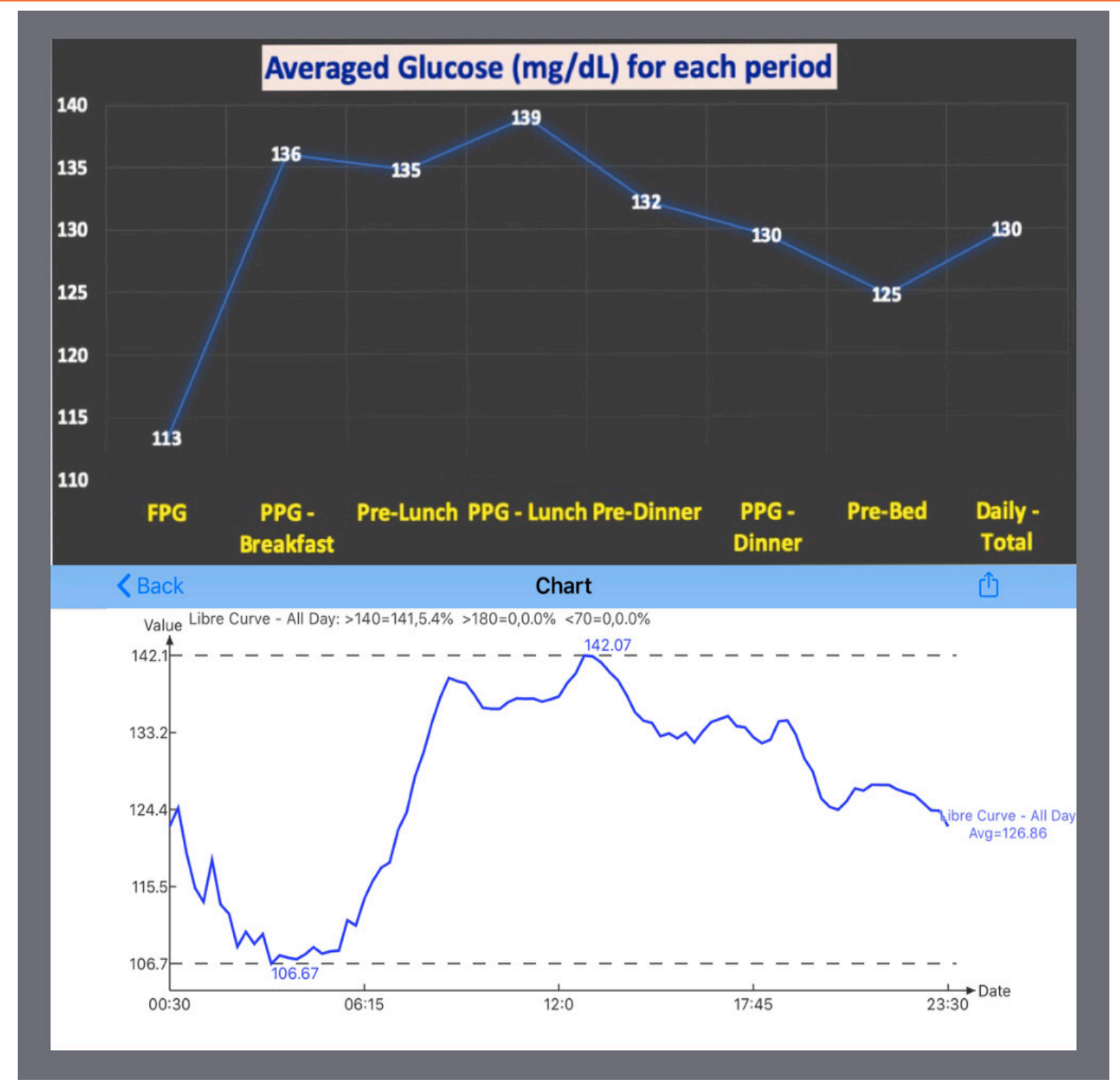

Figure2. 7 subcategories glucose chart and a synthesized daily glucose chart

Here are the seven calculated subcategory glucose values:

(1) FPG: $113 \mathrm{mg} / \mathrm{dL}$

(2) Breakfast PPG: $136 \mathrm{mg} / \mathrm{dL}$

(3) Pre-lunch: $135 \mathrm{mg} / \mathrm{dL}$

(4) Lunch PPG: $139 \mathrm{mg} / \mathrm{dL}$

(5) Pre-dinner: $132 \mathrm{mg} / \mathrm{dL}$

(6) Dinner PPG: $130 \mathrm{mg} / \mathrm{dL}$

(7) Pre-bed: $125 \mathrm{mg} / \mathrm{dL}$

Daily average glucose: $130 \mathrm{mg} / \mathrm{dL}$
Figure 3 displays the average glucose level of the following four categories:

(A) FPG Category: $113 \mathrm{mg} / \mathrm{dL}$

(B) PPG Category: $135 \mathrm{mg} / \mathrm{dL}$

(C) Pre-meals Category: $134 \mathrm{mg} / \mathrm{dL}$

(D) Pre-bed Category: $125 \mathrm{mg} / \mathrm{dL}$

Daily average glucose: $130 \mathrm{mg} / \mathrm{dL}$

The reason pre-meal glucose category is particularly close to PPG is that the author usually eats his daily fruits for essential nutrients and natural vitamin intake during the pre-meal timespan. 


\section{Averaged Glucose for each Category (mg/dL)}

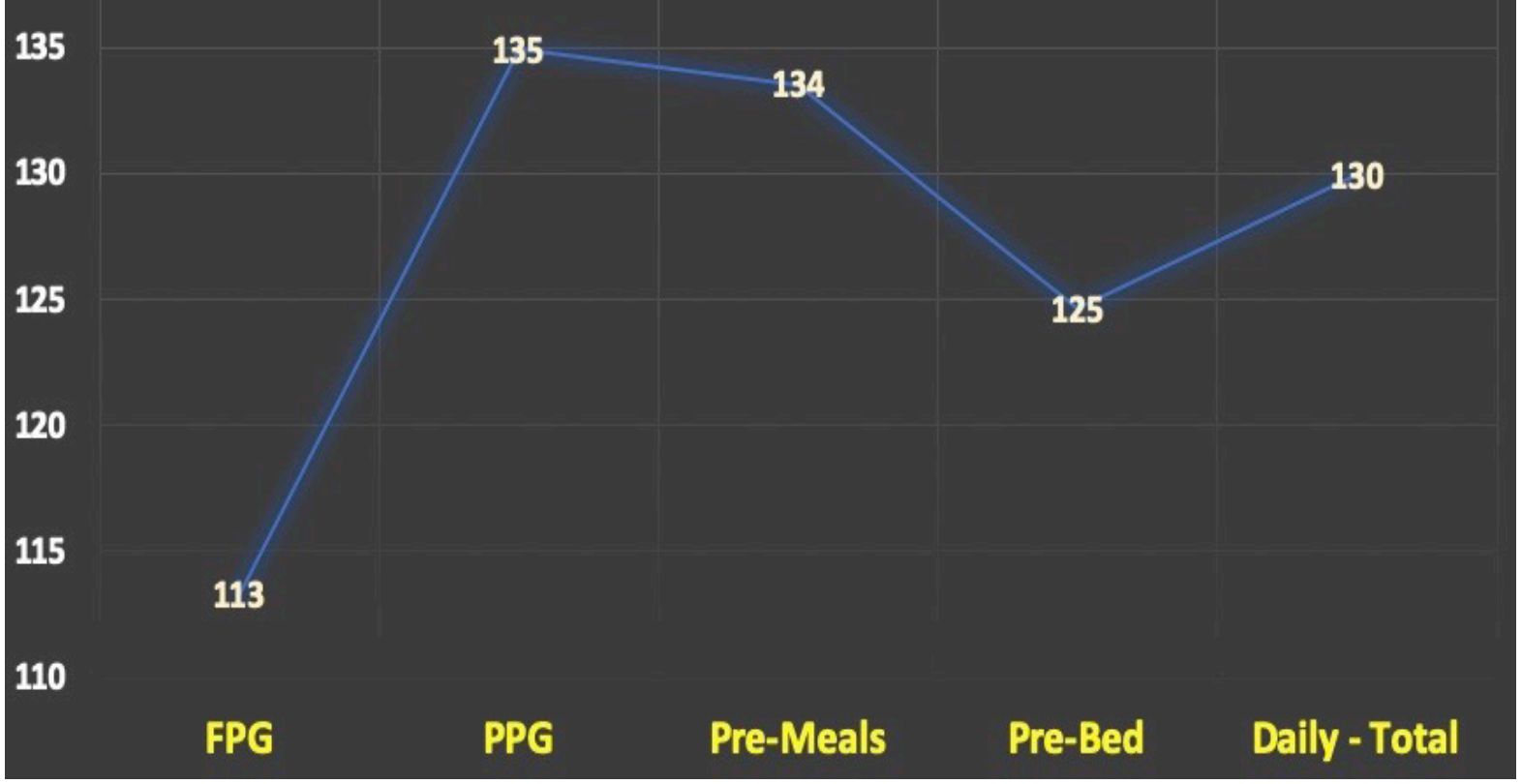

Figure 3. 4 categories of glucose chart and Daily average glucose

Figure 4 exhibits his calculation table using Microsoft Excel.

\begin{tabular}{|c|c|c|c|c|c|}
\hline & Avg Glucose (mg/dL) & Hours & & Glucose Energy & Energy \% \\
\hline FPG & 113 & 7.5 & FPG & 850 & $28 \%$ \\
\hline PPG - Breakfast & 136 & 3.0 & PPG - Breakfast & 408 & $14 \%$ \\
\hline Pre-Lunch & 129 & 2.0 & Pre-Lunch & 258 & $9 \%$ \\
\hline PPG - Lunch & 139 & 3.0 & PPG - Lunch & 417 & $14 \%$ \\
\hline Pre-Dinner & 129 & 3.0 & Pre-Dinner & 387 & $13 \%$ \\
\hline PPG - Dinner & 130 & 3.0 & PPG - Dinner & 389 & $13 \%$ \\
\hline Pre-Bed & 125 & 2.5 & Pre-Bed & 312 & $10 \%$ \\
\hline Daily - Total & 127 & 24.0 & Daily - Total & 3020 & $100 \%$ \\
\hline
\end{tabular}

Figure4. Calculation table using Excel

Figure 5 is the most important conclusive diagram of this particular paper. The calculated "relative energy" levels associated with each category's average glucose are listed below.
(A) FPG Category: 850 (28\%)
(B) PPG Category: 1215 (40\%)
(C) Pre-meals Category: 668 (22\%)
(D) Pre-bed Category: 312 (10\%)

It should be pointed out that the combined period of PPG and pre-meals are contributing $62 \%$ due to food intake, while their total time span is $58 \%$ of a day. This $62 \%$ of glucose energy amount almost occupies $2 / 3$ of the total glucose energy per day. In his previous research findings, the high energy associated with glucose will create more damage to the internal organs which will then lead into various diabetes complications. 


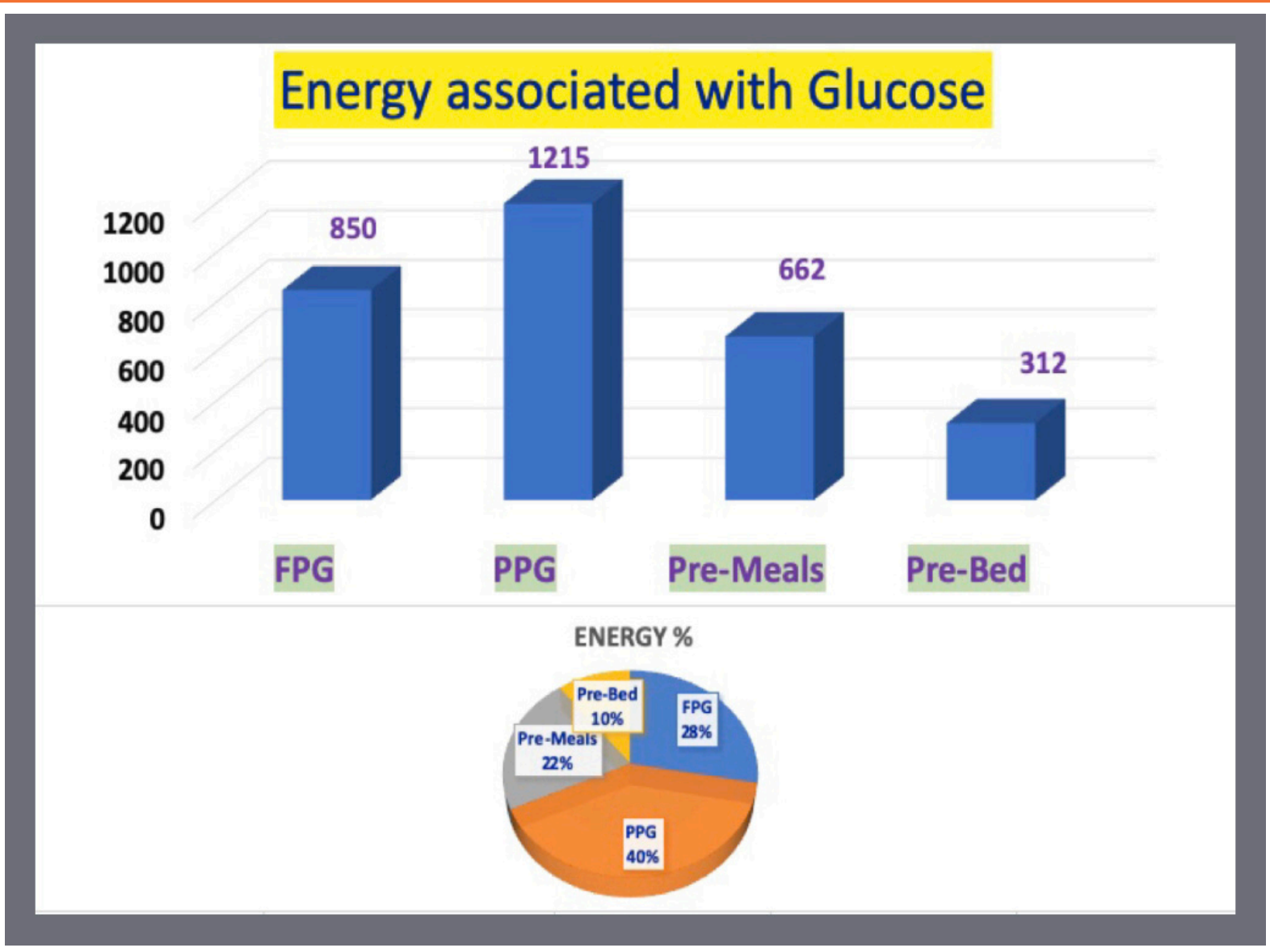

Figure5. Category's relative energy levels and glucose energy distribution \%

\section{CONCLUSIONS}

The author was astonished to discover that his average pre-meal glucose value of $134 \mathrm{mg} / \mathrm{dL}$ as being extremely close to his average PPG value of $135 \mathrm{mg} /$ dL. If he had follow the traditional medical advice and common healthcare practice for the past 8-years by solely depending on the finger-piercing measurement method three times a day at two hours after his first bite of his meals, and did not apply the CGM device two years ago and measured his glucose value $\sim 80$ times a day (every 15 minutes during daytime), he would have never discover this fact. Furthermore, in order to reduce his risk probability of having diabetes complications, he must focus on these two periods: PPG and pre-meals. His pre-meal glucose energy occupying $28 \%$ of the total glucose energy can be controlled more easily than the PPG period. If he can reduce his average pre-meal glucose, he can further improve his health conditions.

Based on the energy theory from mechanical engineering, a deeper understanding of the glucose energy distribution can be achieved by searching the sources that causediabetes complications. From the author's personal data analysis, it seems that another research project on how to reduce his pre-meal glucose is required.

\section{REFERENCES}

[1] Hsu, Gerald C. (2018). Using Math-Physical Medicine to Control T2D via Metabolism Monitoring and Glucose Predictions. Journal of Endocrinology and Diabetes, 1(1), 1-6.

[2] Hsu, Gerald C. (2018). Using Signal Processing Techniques to Predict PPG for T2D. International Journal of Diabetes \& Metabolic Disorders, $3(2), 1-3$.

[3] Hsu, Gerald C. (2018). Using Math-Physical Medicine and Artificial Intelligence Technology to Manage Lifestyle and Control Metabolic Conditions of T2D. International Journal of Diabetes \& Its Complications, 2(3),1-7. 
Segmentation Analysis of Sensor Glucoses and their Associated Energy (GH-Method: Math-Physical Medicine)

[4] Hsu, Gerald C. (2018, June). Using Math-Physical Medicine to Analyze Metabolism and Improve Health Conditions. Video presented at the meeting of the 3rd International Conference on Endocrinology and Metabolic Syndrome 2018, Amsterdam, Netherlands.

[5] Hsu, Gerald C. (2018). Using Math-Physical Medicine to Study the Risk Probability of having a Heart Attack or Stroke Based on Three Approaches, Medical Conditions, Lifestyle Management Details, and Metabolic Index. EC Cardiology, 5(12), 1-9.

Citation: Gerald C. Hsu. Segmentation Analysis of Sensor Glucoses and their Associated Energy (GH-Method: Math-Physical Medicine). Open Access Journal of Internal Medicine. 2020; 3(1): 05-10.

Copyright: (C) 2020 Gerald C. Hsu. This is an open access article distributed under the Creative Commons Attribution License, which permits unrestricted use, distribution, and reproduction in any medium, provided the original work is properly cited. 